\title{
Assessment of autonomic dysfunction in bronchial asthma patients
}

\author{
Raghavendra Sherikar', Mohammed Jaffer ${ }^{2, *}$, Shivakumar J ${ }^{3}$, Usha Sherikar ${ }^{4}$ \\ ${ }^{1,2}$ Assistant Professor, Dept. of Physiology, GSL Medical College, Andhra Pradesh, ${ }^{3}$ Associate Professor, Dept. of Physiology \\ KIMS, Hubli, Karnataka, ${ }^{4}$ Assistant Professor, Dept. of Anatomy, GSL Medical College, Andhra Pradesh, India
}

*Corresponding Author: Mohammed Jaffer

Email: sherikarraghu2010@gmail.com

Received: $11^{\text {th }}$ June, 2018

Accepted: $31^{\text {st }}$ July, 2018

\begin{abstract}
Introduction: Many aspects of airway functions are controlled by autonomic nerves. Bronchospasm, airway edema and excessive mucus secretion may occur due to abnormality in autonomic regulation of airways. All these events lead to airway obstruction in bronchial asthma.

Objective: The aim of the study was to compare the autonomic functions between bronchial asthma patients and normal controls. Materials and Methods: As per American Thoracic Society guidelines thirty bronchial asthma patients in the age group of 1850 years were chosen. Thirty age and sex matched controls were chosen for comparison. Standardized autonomic function tests were done. Statistical analysis was done using students unpaired t' test.

Results: Significantly higher basal heart rate was found in asthmatics in comparison with controls. Parasympathetic function tests showed significantly higher values in asthmatics compared with controls. Statistically significant difference is also found in the sympathetic function tests between asthmatics and normal controls.

Conclusion: Our study shows that autonomic dysfunction is present in asthmatic patients. Parasympathic activity is enhanced in asthmatics, thus supporting the hypothesis of enhanced parasympathetic reactivity as an integral factor in pathophysiology of bronchial asthma.
\end{abstract}

Keywords: Bronchial asthma, Autonomic dysfunction, Parasympathetic tests, Sympathetic tests.

\section{Introduction}

Bronchial asthma is a syndrome characterized by airflow obstruction that varies markedly, both spontaneously and with treatment. Asthmatics harbor a special type of inflammation in the airways that makes them more responsive than non asthmatics to a wide range of triggers, leading to excessive narrowing with consequent reduced airflow and symptomatic wheezing and dyspnea. The increasing global prevalence of asthma, the large burden it imposes on patients, and the associated high health care costs have led to extensive research into its mechanisms and treatment options. ${ }^{1}$

Asthma has also been termed bronchial irritability syndrome. ${ }^{2}$ In response to various stimuli; the bronchial asthma patients show exaggerated bronchoconstriction of airways. This "hyper-reactivity" usually co-exists with airway inflammation, although the pathophysiological mechanisms underlying these changes are not fully understood. These hyper reactive changes are probably associated with abnormal autonomic nervous system control. Cardiac and bronchial autonomic control might be intrinsically related, and that this relationship might be altered in asthmatic individuals. ${ }^{3}$

Airway functions like smooth muscle tone, epithelial cell function, mucous secretion, blood flow, micro vascular permeability and inflammatory mediator release is under the control of autonomic nervous system. ${ }^{4}$

Abnormal regulation of autonomic nerves innervating the tracheo-bronchial tree may lead to bronchospasm, airway edema and excessive mucus secretion. All these are the events which take place in pathogenesis of bronchial asthma. Abnormalities of autonomic nervous system in bronchial asthma patients are generalized and may not be limited to tracheobronchial tree only. Enhanced parasympathetic activity is considered as an important factor in pathogenesis of bronchial hyperactivity. ${ }^{5}$

A review of available literature show varied results as far as the exact nature of autonomic dysfunction in asthmatics. Therefore the present study is undertaken to compare autonomic function test results in uncomplicated asthmatics' with age and sex matched normal subjects.

\section{Materials and Methods}

It is a time bound comparative study of autonomic function tests between bronchial asthma patients and age and sex matched normal healthy subjects. Data was collected from thirty bronchial asthma patients as per American Thoracic Society ${ }^{6}$ guidelines in the age group of 18 to 50 years, thirty age and sex matched controls were selected.

The following inclusion and exclusion criteria were applied for selection process.

\section{Inclusion Criteria}

1. Bronchial asthma patients with disease duration of more than two years.

2. Clinical features of asthma as per American Thoracic Society Guidelines. ${ }^{6}$ 
3. At least two acute asthmatic exacerbations in any given year.

4. Patients age between 18 to 50 years.

5. Not on any medication that may alter the autonomic function for the preceding two weeks of the test.

\section{Exclusion Criteria}

1. Bronchial asthma patients in acute exacerbation.

2. Bronchial asthma patients who had an asthmatic attack within two weeks of study.

3. Age $<18$ or $>50$ years.

4. History of any other disease that is known to produce autonomic dysfunction like diabetes mellitus, hypertension, ischemic heart disease, scleroderma, chronic bronchitis, peripheral nervous system disorders, alcoholics, smokers, those practicing yoga or any other physical training.

Physical Anthropological Indices: Standing height was measured to the nearest $0.5 \mathrm{~cm}$ without foot wear. Weight was recorded without footwear in light weight clothing. The procedures of autonomic function tests were briefed to both subjects and controls. The resting heart rate, respiratory rate and blood pressure were recorded in each participant after 15 minutes rest. OMRON automatic blood pressure monitor model HEM $712 \mathrm{C}$ was used to record systolic and diastolic blood pressures in subjects and controls.

Five standard cardiovascular autonomic function tests were performed, three tests to assess the parasympathetic division and two tests assessing sympathetic division. The following cardiovascular autonomic function tests were performed as per Ewing and Clarke guidelines. ${ }^{7}$

Heart Rate Response to Valsalva Maneuver: Valsalva maneuver is performed by blowing into the mercury manometer upto $40 \mathrm{mmHg}$ of pressure and by maintaining the pressure at that level, while the nose is clipped. Simultaneously ECG recording is carried out. Valsava ratio is derived from the following formula. ${ }^{8,9}$

\section{Longest $\mathrm{R}-\mathrm{R}$ Interval after the maneuver \\ $\overline{\text { Shortest } \mathrm{R}-\mathrm{R} \text { Interval during the maneuver }}$}

A Valsava ratio of ${ }^{7}$ a) 1.21 or greater is taken as normal b) 1.11 to 1.20 is taken as border line c) 1.10 or less was considered as abnormal response.

Heart Rate Variation During Deep Breathing: The subject in asked to lie down and breathe deeply at a rate of 6 breaths /minute. ECG leads are attached for recording. Maximum and minimum heart rate with each respiratory cycle is determined. Mean heart rate during expiration and inspiration are noted down. The result is expressed as the mean of difference between maximum and minimum heart rates for the six measured cycles in beats a minute. ${ }^{7,10} \mathrm{~A}$ difference of a) 15 beats or more per minute was taken as normal b) 11 to 14 beats per minute was taken as border line c) 10 beats or less per minute was taken as abnormal response.

Immediate Heart Rate Response to Standing (30:15 ratio): The subject is asked to lie down in a supine position. ECG leads are applied to record heart rate. The subject is now asked to immediately stand up, while ECG is continuously recorded. Record R-R interval at $15^{\text {th }}$ and $30^{\text {th }}$ beat after standing. 30:15 ratio is calculated from the following formula.

The $\mathrm{R}-\mathrm{R}$ interval at or around the 30 th beat

The $\mathrm{R}-\mathrm{R}$ interval at or around the 15 th beat

A 30:15 ratio of: a) 1.04 and above was considered as normal b) 1.01 to 1.03 was considered as borderline c) 1 or less was considered as abnormal response.

Blood Pressure Response to Immediate Standing: The systolic blood pressure is recorded in lying down posture and immediately after standing. A difference in systolic blood pressure between lying down posture and supine posture is noted down.

A difference of a) $10 \mathrm{~mm} \mathrm{Hg}$ or less was considered normal b) 11 to $29 \mathrm{~mm} \mathrm{Hg}$ was considered borderline c) $30 \mathrm{~mm} \mathrm{Hg}$ or more was considered as abnormal response.

Peripheral sympathetic damage gives an abnormal response. ${ }^{7}$

Blood Pressure Response to Sustained Handgrip: The subject is asked to hold a handgrip dynamometer and grip it to maximum extent. The maximum tension is noted down. Now, the subject is asked to grip the dynamometer at $30 \%$ of maximum tension for a period of 3 minutes. Diastolic blood pressure is recorded before and after the hand grip and the difference is noted down. ${ }^{7}$

A rise of diastolic blood pressure of a) $16 \mathrm{~mm} \mathrm{Hg}$ or more was considered normal b) 11 to $15 \mathrm{~mm} \mathrm{Hg}$ was considered border line c) $10 \mathrm{~mm} \mathrm{Hg}$ or less considered as abnormal response.

\section{Statistical Analysis}

Data was compared between study subjects and control groups using unpaired' test. The level of significance ('p'value) was calculated. A 'p' value of $>0.05$ is not-significant, $<0.05$ is taken as significant and $<0.01$ is taken as highly significant. 


\section{Results}

Table 1: Anthropometric data of controls and subjects

\begin{tabular}{|l|c|c|c|c|}
\hline \multicolumn{1}{|c|}{ Parameters } & Controls(mean \pm SD $)$ & Subjects $($ mean \pm SD) & 't' valve & 'P' value \\
\hline Age $($ years $)$ & $40.43 \pm 5.41$ & $40.76 \pm 4.53$ & 0.258 & $>0.05(\mathrm{NS})$ \\
\hline Height $(\mathrm{cms})$ & $168.7 \pm 5.58$ & $163.8 \pm 5.37$ & 3.486 & $<0.05(\mathrm{~S})$ \\
\hline Weight $(\mathrm{kgs})$ & $63.03 \pm 4.34$ & $60.53 \pm 7.98$ & 1.507 & $>0.05(\mathrm{NS})$ \\
\hline BSA $(\mathrm{sq} \mathrm{ms})$ & $1.70 \pm 0.17$ & $1.66 \pm 0.12$ & 1.101 & $>0.05(\mathrm{NS})$ \\
\hline BMI $\left(\mathrm{ht} / \mathrm{m}^{2}\right)$ & $22.19 \pm 2.09$ & $22.60 \pm 2.47$ & 0.687 & $>0.05(\mathrm{NS})$ \\
\hline
\end{tabular}

NS - Not Significant, S - Significant.

Table 2: Resting heart rate and resting respiratory rate in Controls and Subjects

\begin{tabular}{|l|c|c|c|c|}
\hline \multicolumn{1}{|c|}{ Parameters } & $\begin{array}{c}\text { Controls } \\
(\mathbf{m e a n} \pm \text { SD) }\end{array}$ & $\begin{array}{c}\text { Subjects } \\
(\mathbf{m e a n} \pm \text { SD) }\end{array}$ & $\begin{array}{c}\text { 't' } \\
\text { value }\end{array}$ & 'P' value \\
\hline Resting heart rate (beats/min) & $70.66 \pm 5.03$ & $80.46 \pm 14.97$ & 3.398 & $<0.001(\mathrm{VHS})$ \\
\hline $\begin{array}{l}\text { Resting respiratory rate } \\
\text { (breaths/min) }\end{array}$ & $13.23 \pm 1.4$ & $18.00 \pm 3.29$ & 7.296 & $<0.001(\mathrm{VHS})$ \\
\hline
\end{tabular}

VHS - Very Highly Significant

Table 3: Resting SBP and DBP in controls and subjects

\begin{tabular}{|l|c|c|c|c|}
\hline \multicolumn{1}{|c|}{ Parameters } & Controls (mean \pm SD) & Subjects (mean \pm SD) & 't' value & 'P' value \\
\hline SBP $(\mathrm{mm} \mathrm{Hg})$ & $121.60 \pm 11.62$ & $128.17 \pm 15.07$ & 1.890 & $>0.05(\mathrm{NS})$ \\
\hline $\mathrm{DBP}(\mathrm{mm} \mathrm{Hg})$ & $76.83 \pm 8.20$ & $84.33 \pm 11.71$ & 2.873 & $<0.01(\mathrm{HS})$ \\
\hline
\end{tabular}

NS - Not Significant, HS - Highly Significant

Table 4: Parasympathetic function tests in controls and Subjects

\begin{tabular}{|l|c|c|c|c|}
\hline \multicolumn{1}{|c|}{ Parameter } & Controls $($ mean \pm SD) & Subjects $($ mean \pm SD) & 't' value & 'P' value \\
\hline Valsalva ratio & $1.24 \pm 0.02$ & $1.56 \pm 0.28$ & 6.233 & $<0.001(\mathrm{VHS})$ \\
\hline Deep breathing test & $19.5 \pm 2.62$ & $24.23 \pm 9.3$ & 2.682 & $<0.01(\mathrm{HS})$ \\
\hline 30:15 ratio & $1.13 \pm 0.04$ & $1.35 \pm 0.34$ & 3.452 & $<0.01(\mathrm{HS})$ \\
\hline
\end{tabular}

HS- Highly Significant

Table 5: Sympathetic function tests in controls and subjects

\begin{tabular}{|l|c|c|c|c|}
\hline \multicolumn{1}{|c|}{ Parameter } & $\begin{array}{c}\text { Controls } \\
(\mathbf{m e a n} \pm \mathbf{S D})\end{array}$ & $\begin{array}{c}\text { Subjects } \\
(\mathbf{m e a n} \pm \mathbf{S D})\end{array}$ & 't' value & 'P' value \\
\hline Fall in SBP on standing (mm Hg) & $8.60 \pm 2.17$ & $14.03 \pm 7.23$ & 3.933 & $<0.001(\mathrm{VHS})$ \\
\hline Rise in DBP(mm Hg) to Hand grip & $19.93 \pm 3.39$ & $9.46 \pm 3.54$ & 11.674 & $<0.001(\mathrm{VHS})$ \\
\hline
\end{tabular}

VHS: Very Highly Significant

\section{Discussion}

Anthropometric data in Table 1 did not show any significant difference between control and study group except for height. Height does not have any impact on the autonomic function. As per Table 2, there is a significant increase in resting heart rate in asthmatics as compared to controls. Samadhan P M et al., ${ }^{5}$ Prabhat $\mathrm{KD}$ et al, ${ }^{2}$ Garrard et $\mathrm{al}^{12}$ and Bal BS et al. ${ }^{13}$ also found that the resting heart rate was significantly higher in asthmatics compared with non-asthmatics. The increase in resting heart rate suggests either an increased sympathetic tone or reduced parasympathetic tone. The resting respiratory rate in asthmatics $(18 \pm 3.29$ breaths/min) was significantly increased compared to controls (13.23 \pm 1.4 breaths $/ \mathrm{min})$.

As per Table 3 SBP was numerically higher in asthmatics, it was not statistically significant. The DBP in asthmatics was significantly higher compared to controls. Samadhan PM et al. $^{5}$ also found insignificantly higher basal systolic and diastolic blood pressures in asthmatics compared to controls. This may be due to $\alpha$-adrenergic hyperresponsiveness in asthmatics.

As per Table 4, the values of Valsalva ratio, deep breathing test and 30:15 ratio are all significantly higher in asthmatics compared with normal subjects. This is suggestive of increased parasympathetic response in asthmatics. Prabhat $\mathrm{KD}$ et $\mathrm{al}^{2}$ also recorded significantly higher values for Valsalva ratio and 30:15 ratio. Kallenbach et al ${ }^{14}$ recorded higher values for deep breathing test.

The heart rate increases during inspiration and decreases during expiration, this is called as sinus arrhythmia. This occurs primarily because of variation in the parasympathetic outflow to the heart with phases of respiration..$^{15}$ Exaggerated parasympathetic outflow 
to heart may have led to higher values of deep breathing tests in asthmatics. In asthmatics more and more air is trapped in the lungs. During inspiration increased stretch receptor stimulation may lead to strong suppression of dorsal vagal nucleus. This results in drastic reduction of vagal tone and is the cause of abnormal HRV in our subjects. ${ }^{16} 30: 15$ ratio (immediate HRR to standing) was significantly higher in asthmatics $(1.35 \pm 0.34$ beats $/ \mathrm{min})$ compared to controls $(1.13 \pm 0.04$ beats/min). The initial cardiac acceleration upon standing is an exercise reflex which withdraws parasympathetic tone and the subsequent changes are baroreceptors mediated which enhance sympathetic tone. Most of the heart rate changes are due to parasympathetic withdrawal. ${ }^{17} \mathrm{~A}$ higher $30: 15$ ratio in our subjects thus suggests a heightened basal parasympathetic tone. Prabhat K D et al. ${ }^{2}$ also found a higher HRV in asthmatics but was not statistically significant. Gupta $\mathrm{S}$ et $\mathrm{al}^{18}$ also observed heightened cardiovascular responses to tests of parasympathetic function as compared to controls.

All the three parasympathetic tests show statistically increased values, suggesting hyperresponsiveness of parasympathetic system in asthmatics compared to the controls. The parasympathetic nervous system has a role in reflex bronchoconstriction and it is generally accepted that this effect is exaggerated in asthmatics, causing a hyper-responsiveness to cold air, rapid breathing, sulphur dioxide, citric acid and histamine. ${ }^{19}$ Our study supports the hypothesis of enhanced parasympathetic hyper activity as an important factor in the pathogenesis of asthma. ${ }^{5}$ Molfino NA et al. ${ }^{20}$ suggests that enhanced cholinergic airway responsiveness is a contributing factor to the development of bronchial asthma. The abnormally increased airway tone and hyper-reactivity in asthma might be caused by either (i) an increased release of acetylcholine from nerves, or (ii) increased sensitivity of the post-junctional muscarinic receptors. ${ }^{21}$

Fall in SBP (Table 5) on immediate standing in asthmatic subjects was $14.03 \pm 7.23 \mathrm{~mm} \mathrm{Hg}$; it was significantly higher compared to those observed in the controls $(8.06 \pm 2.17 \mathrm{~mm} \mathrm{Hg})$. On immediate standing, there is pooling of blood in the large veins of lower extremities leading to fall in systolic blood pressure. This activates baroreceptor reflex, leading to sympathetic stimulation. This in turn causes increased force of contraction of heart thus correcting the fall in systolic blood pressure and further preventing the fall in systolic blood pressure. Thus, higher and significant fall in SBP on immediate standing in our subjects denotes sympathetic nervous system dysfunction.

There was significantly lower rise in DBP to hand grip test (Table 5) in asthmatics compared to controls. The pressor response to handgrip is accompanied by increased cardiac output and no change in calculated systemic vascular resistance. After propanolol, handgrip resulted in increased peripheral resistance and an equivalent rise in arterial pressure, but no increase in cardiac output. It was concluded that the increase in resistance was the result of sympathetically induced vasoconstriction..$^{22}$ Thus a lesser and significant rise in DBP to sustained hand grip test in our subjects is suggestive of sympathetic nervous system dysfunction in asthmatics.

Bhavneesh Sharma et al. ${ }^{23}$ reported in their study that out of 30 asthmatics, 14 had pure parasympathetic dysfunction, 12 had both parasympathetic and sympathetic dysfunction and 4 had isolated sympathetic dysfunction.

The complexity of pulmonary autonomic innervation, its pulmonary effect, and of autonomic interaction between the lungs and the heart is considerable and the present knowledge may be meager while interpreting cardiovascular autonomic reflex tests to assess pulmonary autonomic status. The interpretation of impaired cardiovascular reflex activity is complex, as the methods of autonomic tests are indirect and abnormal test results cannot simply be equated with a lesion in autonomic nerves, since circulating hemodynamics, in addition, are also involved in cardiovascular reflex activity.

\section{Conclusion}

Autonomic dysfunction is present in bronchial asthma patients. Both parasympathetic and sympathetic components are affected. Tests assessing parasympathetic division showed significantly higher values in asthmatics compared to controls, suggesting enhanced parasympathetic activity. Significant differences were also found in the values of sympathetic function tests between asthmatics and controls, suggesting sympathetic dysfunction. Enhanced parasympathetic activity observed in our study is considered as an important factor in pathogenesis of bronchial hyper reactivity. Though sympathetic nervous system is affected, it does not directly take part in controlling the airways. Sympathetic function test demonstrate the function of sympathetic efferents on the vessels, thus it cannot be directly equated with bronchial hyper reactivity. Sympathetic dysfunction observed here may be a part of generalized autonomic dysfunction in asthmatics, but may not contribute to pathogenesis of asthma.

\section{References}

1. Peter J. Barnes, Harrison's principles of internal medicine $18^{\text {th }}$ edn. USA Mc Graw Hill Co; 2012:2:2102-2115.

2. Prabhat KD, Manoj L, Sanjay M, Suresh KJ. Clinical dysautonia in patients with bronchial asthma. Chest. 1990;98:1408-13.

3. Low PA, Tomalia VA, Ki-Jong P. Autonomic Function Tests: Some Clinical Applications. J Clin Neurol. 2013;9(1):1-8.

4. Manoj Kumar, Verma NS, Tiwari S, Pandey US, Sympathetic hyperactivity in patients of bronchial asthma. Indian J Physiol Pharmacol. 2005;49(1):89-94. 
5. Samadhan P. Mitkari, Pushpa A, Pazare, Sachin M. Pawar. Autonomic dysfunction in patients with bronchial asthma. Int J Biol Med Res. 2011;2(4):852-855.

6. American Thoracic Society, Standards for the diagnosis and care of patients with chronic obstructive pulmonary disease (COPD) and asthma. Am Rev Respir Dis. 1987; 136:225-244.

7. DJ Ewing, BF Clarke. Diagnosis and management of diabetic autonomic neuropathy. Br Med J. 1982;285:916918.

8. Gillan P Lawrence, Philip D Home, Alan Murray. Repeatability of measurements and sources of variability in tests of cardiovascular autonomic function. Br Heart $J$. 1992;68:205-11.

9. Seema Kumar. A study of autonomic nervous system status in children of asthmatic parents. Indian J Physiol Pharmacol. 2012;56(1):74-79

10. B K Bajaj, M P Agarwal, B K Ram. Autonomic neuropathy in patients with hepatic cirrhosis. Postgrad Med J 2003; 79; 408-411.

11. Devi T, Kanan W, Singh T, Asoka W, Benjamin L. A study of sympathetic nervous system in bronchial asthma. J Med Soc. 2012;26:159-62.

12. Garrad CS, Seidler A, Mc Kibben A, Mc Alpine LE, Gordon D. Spectral analysis of heart rate variability in bronchial asthma. Clic Autonom Research. 1992;2:105111.

13. Bal BS, Multani AS, Avinash J, Singh TP, Salwas S, Shivcharan. Study of autonomic dysfunction in cases of bronchial asthma. J Assos Phy Ind, 2003;51:1203-1204.

14. Kallenbach JM, Webster T, Dowdeswell R, Reinach SG, Scot Milar RN, Zwi S. Reflex heart rate control in asthma: evidence of parasympathetic over activity. Chest. 1985;87(5):644-648

15. William F. Ganong Cardiovascular regulatory mechanisms. Review of Medical Physiology $22^{\text {nd }}$ edn. Mc Graw Hill: 2005:597-635.
16. Dunill MS. The pathology of asthma, with special references to changes in the bronchial mucosa. J Clin Pathol. 1960:13;27-33.

17. Misra UK, Kalita J, Autonomic nervous system testing, Clinical Neurophysiology, New Delhi: B.I. Churchill Livingstone Pvt. Limited: 2001:97-113.

18. Gupta S, Dolwani S, A study of autonomic status and its effects on ventilator functions in bronchial asthma. Indian J Chest Dis Allied Sci. 1996;38(3):147-56.

19. Nadel JA. Concluding remarks: cough and expectoration. Eur J Respir Dis Suppl. 1980;110:257-260.

20. Molfino NA, Slutsky AS, Julia-Serda G, Hoffstein V, Szalai JP, Chapman KR, et al. Assessment of airway tone in asthma. Am Rev Respir Dis. 1993;148:1238-1243.

21. Scalvini S, Porta R, Zanelli E, Volterrani M, Vitacca M, Pagani $\mathrm{M}$ et al. Effects of oxygen on autonomic nervous system dysfunction in patients with chronic obstructive pulmonary disease. Eur Respir J. 1999;13(1):119-124.

22. Martin CE, James AS, Leon DF, Thomson ME, Reddy PS, Leonard J. Autonomic mechanisms in hemodynamic responses to isometric exercise. The Journal of Clinical Investigation. 1974;54:104-115.

23. Bhavneesh Sharma. A study of autonomic dysfunction in adult asthma patients at a tertiary care centre. Chest. 2003.

How to cite this article: Sherikar R, Jaffer M, Shivakumar J, Sherikar U. Assessment of autonomic dysfunction in bronchial asthma patients. Indian $\mathbf{J}$ Clin Anat Physiol. 2018;5(4):530-534. 